\title{
Uso do teste Lercafé para a caracterização de danos em sementes de cafeeiro
}

\author{
João Batista Zonta(1), Eduardo Fontes Araujo(1), Roberto Fontes Araujo(2) e Múcio Silva Reis ${ }^{(1)}$
}

\begin{abstract}
(1)Universidade Federal de Viçosa, Departamento de Fitotecnia, Avenida P.H. Rolfs, s/no, Campus Universitário, CEP $36570-000$ Viçosa, MG. E-mail: jobazonta@hotmail.com, efaraujo@ufv.br, msreis@ufv.br ${ }^{(2)}$ Empresa de Pesquisa Agropecuária de Minas Gerais, Vila Gianneti, no 47, Campus Universitário, CEP 36570-000 Viçosa, MG. E-mail: rfaraujo@ufv.br
\end{abstract}

\begin{abstract}
Resumo - O objetivo deste trabalho foi avaliar a utilização do teste Lercafé, para estimar a germinação e caracterizar diferentes tipos de danos em sementes de cafeeiro. Utilizaram-se sementes de cafeeiro arábica cultivar Catuaí IAC 44, submetidas aos seguintes tratamentos: sementes sem dano, sementes com dano por secagem a 40 e $60^{\circ} \mathrm{C}$, e sementes brocadas. As sementes foram avaliadas pelos testes de germinação e Lercafé. Em relação aos dois tipos de danos, os resultados de germinação, estimada pelo Lercafé, apresentaram alta correlação com os obtidos pelo teste de germinação. O dano por secagem à alta temperatura caracterizou-se pelo aparecimento de manchas esverdeadas espalhadas, que atingiram parcial ou totalmente o endosperma da semente. $\mathrm{O}$ dano por broca caracterizou-se por uma depressão circundada por um anel de coloração verde. O teste Lercafé é eficiente para estimar a germinação e caracterizar os danos por secagem à alta temperatura e os causados por broca, em sementes de cafeeiro.
\end{abstract}

Termos para indexação: Coffea arabica, Hypothenemus hampei, hipoclorito de sódio, teste de germinação.

\section{Characterization of injuries in coffee seeds through Lercafé test}

\begin{abstract}
The objective of this work was to evaluate the use of the Lercafé test for estimating the germination and characterizing different types of injuries in coffee seeds. Seeds of arabica coffee cultivar Catuaí IAC 44 were submitted to the following treatments: nondamaged seeds, heat damage (at 40 and $60^{\circ} \mathrm{C}$ ), and bug damage. Seeds were assessed by the tests of germination and Lercafé. The germination results estimated by Lercafé test had high correlation with the results from the germination test for the two types of injuries. The heat damage, by drying seeds at high temperatures, was characterized by scattered green stains, partially or totally covering the seed endosperm. A sunken lesion surrounded by a green ring characterized the damage by coffee berry borer. Lercafé test is efficient to estimate the germination and to characterize the injuries by heat and coffee berry borer, in coffee seeds.
\end{abstract}

Index terms: Coffea arabica, Hypothenemus hampei, sodium hypochlorite, germination test.

\section{Introdução}

As sementes de cafeeiro, quando ainda no campo, estão sujeitas a alguns danos, causados principalmente por insetos-praga, entre os quais se destaca a broca-do-café (Hypothenemus hampei) que, segundo Damon (2000), é a principal praga do cafeeiro em vários países produtores como Brasil, Colômbia e Vietnã. A broca-do-café é uma praga presente em grãos verdes e maduros de café, que não causa danos às folhas, caules e ramos (Damon, 2000; Reis, 2004). As fêmeas adultas abrem galerias no endosperma da semente, onde depositam os ovos. As larvas e os adultos alimentam-se das sementes e provocam redução no peso dos grãos, que pode variar de 5 a $20 \%$, depois de processado (Borbón-Martínez et al., 2000). Após a colheita e as etapas de preparo das sementes, outro tipo de dano muito comum está relacionado à alta temperatura utilizada no processo de secagem.

Os danos por exposição à alta temperatura ocorrem principalmente durante o processo de secagem, em que as sementes sofrem mudanças físicas, provocadas por mudança de temperatura e umidade que ocasionam expansão, contração e alterações na densidade e porosidade. A secagem de grãos, na prática, é uma operação crítica, que requer maior gerenciamento da qualidade, porque tanto a qualidade fisiológica (germinação evigor) quanto aidentidade genética (pureza varietal) devem ser preservadas (Baudet et al., 1999). Vieira et al. (2007) concluíram que a secagem rápida é prejudicial às sementes de cafeeiro, independentemente das condições de armazenamento. 
Os danos causados pela broca-do-cafeeiro são significativos para a cultura, visto que esta se constitui na mais importante praga dos cafezais, em determinadas regiões, em razão de poderem atacar os frutos nos estádios denominados verdes, maduros ou cerejas, e até mesmo secos e armazenados (Pimenta \& Vilela, 1999). A semente atacada pode ou não ser destruída, a depender do número de larvas que se alimentam dela (Reis et al., 1984).

Atualmente, os testes mais utilizados para detectar e quantificar danos em sementes são: o "verde rápido" ("fast green") e a tintura de iodo para sementes de milho (Marcos Filho et al., 1987); o teste de tetrazólio para sementes de soja; e a análise de imagem digital e de raio x para diversas espécies (Battisti et al., 2000; Oliveira, 2000; Machado, 2002; Flor et al., 2004). Vieira et al. (1998) utilizaram solução de tetrazólio em sementes de café, para determinar danos mecânicos. Em estudo realizado em sementes de cafeeiro, Reis (2004) verificou que o teste Lercafé é eficiente para estimar a viabilidade delas; o autor verificou que determinadas concentrações de hipoclorito de sódio, utilizadas como solução de embebição, reagem com partes deterioradas do endosperma, e ocorre o aparecimento da coloração verde nessas áreas. Assim, a exemplo do teste de tetrazólio, supõe-se poder utilizar o teste Lercafé, para detectar, por meio dessa coloração, diferentes tipos de danos encontrados em sementes de cafeeiro.

Objetivou-se com este trabalho, caracterizar, por meio do Lercafé, diferentes tipos de danos em sementes de cafeeiro.

\section{Material e Métodos}

O experimento foi conduzido no Laboratório de Pesquisa de Sementes, do Departamento de Fitotecnia, da Universidade Federal de Viçosa (UFV), em Viçosa, MG, em 2006 e 2007. Foram utilizadas sementes de cafeeiro Coffea arabica L., cultivar IAC Catuaí 44, provenientes da Fazenda Experimental do Vale do Piranga/Empresa de Pesquisa Agropecuária de Minas Gerais (Epamig).

Os frutos foram colhidos manualmente, no estádio denominado cereja e, após a colheita, foram submetidos aos processos de despolpamento e degomagem (fermentação em água por 24 horas), para a retirada da casca e mucilagem, respectivamente. As sementes foram lavadas em água corrente e dispostas sobre telado, à sombra, para remoção do excesso de umidade; em seguida, foram secadas à sombra, em sacos de filó de 10x15 cm, com aproximadamente 1,3 kg de sementes em cada embalagem, até atingir os teores de água desejados. De acordo com o tipo de dano, foram realizados os experimentos a seguir relatados.

As sementes com $40 \%$ de teor de água inicial (base úmida) foram secadas a $40 \pm 3^{\circ} \mathrm{C}$ e $60 \pm 3^{\circ} \mathrm{C}$, em estufa de circulação forçada de ar, até atingir 33, 23 e $13 \%$ de teor de água (base úmida). Durante a operação de secagem, foram realizadas pesagens periódicas, até se atingirem os teores de água final desejados. Depois da secagem, as sementes foram mantidas em dessecador até a temperatura ambiente, quando foram acondicionadas em embalagem impermeável, em condições de laboratório. Os tratamentos foram testemunha e sementes secadas a: $40^{\circ} \mathrm{C}$ até $33 \%$ de teor de água; $40^{\circ} \mathrm{C}$ até $23 \%$ de teor de água; $40^{\circ} \mathrm{C}$ até $13 \%$ de teor de água; $60^{\circ} \mathrm{C}$ até $33 \%$ de teor de água; $60^{\circ} \mathrm{C}$ até $23 \%$ de teor de água; e $60^{\circ} \mathrm{C}$ até $13 \%$ de teor de água.

As sementes danificadas foram obtidas com a infestação em $1 \mathrm{~kg}$ de sementes com $33 \%$ de teor de água, acondicionadas em embalagem impermeável com insetos adultos da espécie Hypothenemus hampei, e mantidas em condições de laboratório. Periodicamente, observou-se o lote de sementes, até serem constatados os primeiros insetos adultos emergentes. A partir desse momento, de dois em dois dias, separavam-se os insetos emergidos das sementes, com a finalidade de se evitar a reinfestação e, ao mesmo tempo, separavamse as sementes danificadas pela broca, até ser atingido o número suficiente para a realização dos ensaios. Foram consideradas sementes atacadas ou danificadas pela broca as que apresentavam um ou mais orifícios de emergências dos insetos adultos. Os tratamentos foram obtidos com a mistura de sementes sem danos e sementes danificadas, no total de 1.600 sementes por lote. Os tratamentos consistiram de sementes danificadas, nas percentagens seguintes: $0 \%$, lote 1 ; $5 \%$, lote $2 ; 10 \%$, lote 3 ; e $15 \%$, lote 4 .

As sementes de cada tratamento, dos dois experimentos, foram avaliadas pelo teste Lercafé e pelo teste de germinação, conforme descrito a seguir.

Quatro repetições de 50 sementes, de cada tratamento, tiveram seu pergaminho removido manualmente. Cinqüenta sementes, ou volume correspondente, foram 
imersas em $100 \mathrm{~mL}$ de hipoclorito de sódio $(2,5 \%$ de cloro ativo), em caixas do tipo gerbox, com telado de plástico, para melhor envolvimento das sementes pela solução. As caixas com as sementes foram levadas para câmara do tipo $\mathrm{BOD}$, a $25^{\circ} \mathrm{C}$, onde permaneceram por três horas. Após esse período, as sementes foram lavadas em água corrente por $90 \mathrm{~s}$ e foram imersas em água destilada por $40 \mathrm{~min}$; posteriormente, foram dispostas sobre bancada para avaliação. Após a avaliação visual, as sementes foram fotografadas, para se caracterizarem os tipos de danos. De acordo com o tipo de dano encontrado e a presença do embrião, determinaram-se as percentagens de sementes germináveis e não germináveis, conforme adaptação da metodologia descrita por Reis (2004).

Utilizaram-se quatro repetições de 50 sementes, sem pergaminho, removido manualmente, por tratamento, as quais foram semeadas em papel germitest (três folhas) umedecido com água destilada, em quantidade equivalente a 2,5 vezes o peso do papel seco. Foram confeccionados rolos que foram mantidos em germinador a $30^{\circ} \mathrm{C}$. As avaliações foram efetuadas aos 15 e 30 dias após a semeadura, e os resultados foram expressos em percentagem média de plântulas normais (Brasil, 1992).

Para cada experimento, foi utilizado o delineamento inteiramente casualizado, com quatro repetições. Os dados foram submetidos à análise de variância, e as médias foram comparadas entre si, pelo teste de Tukey, a $5 \%$ de probabilidade. Foram calculados os coeficientes de correlação de Pearson entre o teste Lercafé e o teste de germinação, tendo sido a significância dos valores de correlação determinada pelo teste t, a $1 \%$ de probabilidade (Pimentel-Gomes, 2000).

\section{Resultados e Discussão}

Após o teste Lercafé, foram observadas, em relação às duas temperaturas de secagem $\left(40\right.$ e $\left.60^{\circ} \mathrm{C}\right)$, sementes com diferentes características visuais e, assim, para a determinação da viabilidade dos lotes, estas foram divididas em cinco classes (Figura 1).

As sementes da classe 1 apresentam endosperma de coloração clara e embrião visível; as de classe 2 apresentam endosperma de coloração clara, com até $10 \%$ de área com coloração esverdeada, exceto no embrião. Quando as sementes apresentam de 10 a $40 \%$ de área com coloração esverdeada, exceto na região do embrião, pertencem à classe 3; e com mais de $40 \%$ de área com coloração esverdeada ou com coloração na região do embrião pertencem à classe 4 . As sementes das classe 5 apresentam endosperma de coloração clara, sem embrião visível. Sementes das classes 3, 4 e 5 foram consideradas não germináveis. A partir das diferentes classes de sementes encontradas, caracterizou-se como dano por secagem à alta temperatura aquelas com manchas esverdeadas espalhadas, que atingiram parcial ou totalmente o endosperma.

Observando-se os valores de germinação obtidos pelos testes Lercafé e de germinação (Tabela 1),

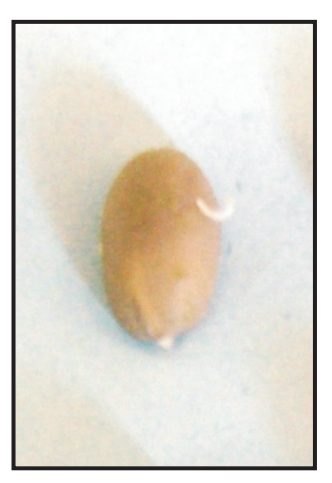

Classe 1

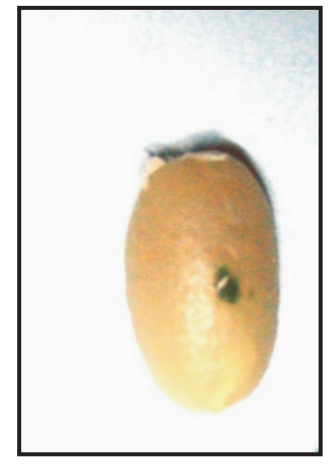

Classe 2

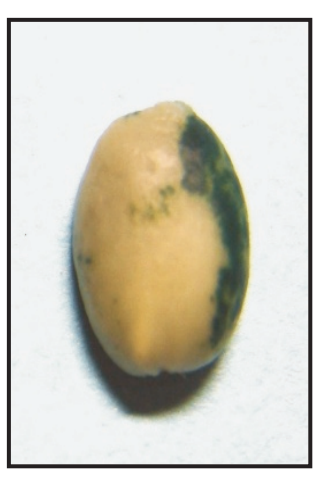

Classe 3

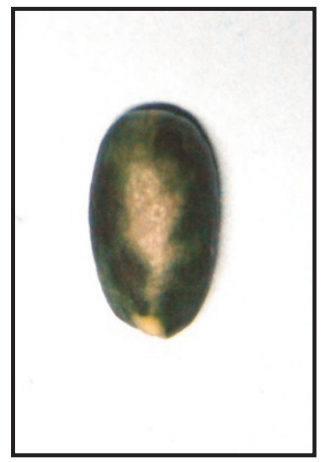

Classe 4

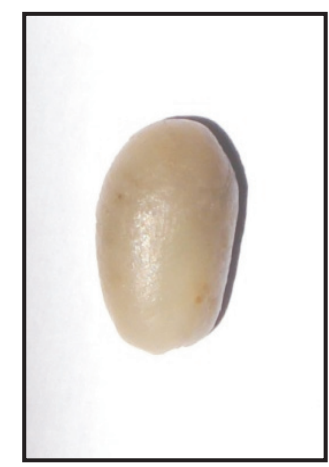

Classe 5

Figura 1. Classificação de sementes de cafeeiro pelo teste Lercafé. Classe 1, endosperma de coloração clara e embrião visível; classe 2, endosperma de coloração clara, com até $10 \%$ de área com coloração esverdeada, exceto na região do embrião; classe 3, endosperma de coloração clara, com 10 a 40\% de área com coloração esverdeada, exceto na região do embrião; classe 4 , endosperma de coloração clara, com mais de 40\% de área com coloração esverdeada; classe 5, endosperma de coloração clara, sem embrião visível. 
nota-se que este último foi eficiente em detectar a diferença na percentagem de germinação que havia entre os diferentes tratamentos, já que a diferença na percentagem de germinação encontrada pelo teste Lercafé correspondeu à diferença encontrada pelo teste de germinação. Os tratamentos nos quais as sementes foram submetidas à secagem em alta temperatura, quanto maior a temperatura e maior o tempo de exposição, maior foi a queda do poder germinativo da semente. Quando as sementes foram secadas a $40^{\circ} \mathrm{C}$, a percentagem de germinação decresceu gradativamente, e não houve germinação quando atingiu $13 \%$ de teor de água. Nos tratamentos em que as sementes foram secadas a $60^{\circ} \mathrm{C}$, a germinação teve uma queda acentuada ao atingir 33\% de teor de água; até 23 e 13\% de teor de água, as sementes perderam totalmente o poder germinativo. Assim, mostra-se que o aquecimento do ar de secagem pode reduzir o poder germinativo das sementes de cafeeiro, fato este comprovado por Barboza \& Herrera (1990), quando realizaram a secagem de sementes de cafeeiro com ar à temperatura ambiente e aquecido a $40^{\circ} \mathrm{C}$. Araújo et al. (1989) observaram que a temperatura do ar de secagem de $50^{\circ} \mathrm{C}$ foi prejudicial à germinação das sementes (efeito imediato), enquanto o efeito prejudicial das temperaturas de 30 e $40^{\circ} \mathrm{C}$ só ocorreu após o armazenamento (efeito latente). Os autores também verificaram que a secagem a 60 e $70^{\circ} \mathrm{C}$ causou a morte de todas as sementes.

A intensidade na qual a mancha escura aparece no endosperma da semente depende da temperatura e do tempo de exposição a esta (Tabela 1). Na temperatura de $40^{\circ} \mathrm{C}$, das sementes secadas até 33 e $23 \%$ de teor de água, sem se considerarem as da classe 1 (sem dano), a maior percentagem de sementes pertence às classes 2 e 3 ; das sementes secadas até $13 \%$ de teor de água, a maior percentagem pertence às classes 3 e 4. Na temperatura de secagem de $60^{\circ} \mathrm{C}$, houve maior percentagem de sementes da classe 2 , quando secadas até $33 \%$ de teor de água, e da classe 4 , quando secadas até 23 e $13 \%$ de teor de água.

Verificou-se correlação positiva e significativa $\left(r=0,9982\right.$, sementes secadas a $40^{\circ} \mathrm{C}$; e $r=0,9936$, sementes secadas a $60^{\circ} \mathrm{C}$ ) entre os resultados obtidos pelos testes Lercafé e de germinação. $\mathrm{O}$ dano por secagem a 40 e $60^{\circ} \mathrm{C}$ influenciou diretamente a percentagem de germinação das sementes, fato evidenciado pelos dois testes utilizados, além de comprovar que o Lercafé pode ser utilizado para o controle da qualidade das sementes durante a operação de secagem.

Após o teste Lercafé, foram observadas sementes com diferentes características e, para a determinação da viabilidade dos lotes, elas foram divididas em quatro classes (Figura 2). As da classe 1, classificadas como germináveis, apresentaram endosperma de coloração clara e embrião visível. As sementes da classe 2, da mesma maneira que as da classe 1 , apresentaram endosperma de coloração clara, embrião visível, porém com lesão típica de ataque de broca, localizada distante do embrião. As sementes da classe 2 também foram consideradas germináveis, mas, por incidência de fungo em razão da lesão causada pela broca, apresentaram, em alguns casos, baixo poder germinativo. As sementes da classe 3 apresentaram endosperma de coloração clara, embrião visível, com lesão típica resultante de ataque de broca, localizada próxima ao embrião. O dano por ataque da broca-do-cafeeiro caracteriza-se por

Tabela 1. Resultados dos testes Lercafé e de germinação de sementes de cafeeiro, com diferentes teores de água final, depois da secagem em diferentes temperaturas ${ }^{(1)}$.

\begin{tabular}{|c|c|c|c|c|c|c|c|c|}
\hline \multirow[t]{2}{*}{$\begin{array}{l}\text { Temperatura de } \\
\text { secagem }\left({ }^{\circ} \mathrm{C}\right)\end{array}$} & \multirow[t]{2}{*}{$\begin{array}{l}\text { Teor de água } \\
\text { final (\%) }\end{array}$} & \multirow[t]{2}{*}{$\begin{array}{c}\text { Teste de } \\
\text { germinação (\%) }\end{array}$} & \multirow[t]{2}{*}{$\begin{array}{l}\text { Germinação } \\
\text { Lercafé }(\%)^{(2)}\end{array}$} & \multicolumn{5}{|c|}{$\begin{array}{c}\text { Teste Lercafé } \\
\text { Classes }^{(3)}\end{array}$} \\
\hline & & & & 1 & 2 & 3 & 4 & 5 \\
\hline \multirow[t]{4}{*}{40} & $40^{(4)}$ & 91a & $97 a$ & 97 & 0 & 0 & 0 & 3 \\
\hline & 33 & $81 b$ & $92 b$ & 83 & 9 & 6 & 0 & 3 \\
\hline & 23 & $71 \mathrm{c}$ & $83 c$ & 74 & 9 & 12 & 4 & 2 \\
\hline & 13 & $0 \mathrm{~d}$ & $16 \mathrm{~d}$ & 14 & 2 & 50 & 33 & 1 \\
\hline$\overline{C V}(\%)$ & & 5,58 & 3,52 & 5,13 & 29,43 & 31,25 & $\begin{array}{l}59,26 \\
\end{array}$ & 32,99 \\
\hline \multirow[t]{4}{*}{60} & $40^{(4)}$ & $91 \mathrm{a}$ & $97 a$ & 97 & 0 & 0 & 0 & 3 \\
\hline & 33 & $60 \mathrm{~b}$ & $76 \mathrm{~b}$ & 31 & 45 & 16 & 7 & 2 \\
\hline & 23 & $0 \mathrm{c}$ & $13 c$ & 1 & 12 & 20 & 68 & 1 \\
\hline & 13 & $0 \mathrm{c}$ & $5 \mathrm{~d}$ & 0 & 5 & 8 & 86 & 0 \\
\hline$\overline{C V}(\%)$ & & 15,34 & 5,55 & 15,37 & 33,81 & 53,78 & 19,54 & 49,23 \\
\hline
\end{tabular}

${ }^{(1)}$ Médias seguidas de letras iguais, nas colunas, não diferem entre si pelo teste de Tukey, a $5 \%$ de probabilidade. ${ }^{(2)}$ Corresponde às classes 1 e $2 .{ }^{(3)} \mathrm{Classes} 1$ e 2: germináveis; classes 3, 4 e 5: não germináveis. ${ }^{(4)}$ Testemunha (sem secagem). 
uma depressão, circundada por um anel de coloração verde. Essa depressão é característica de ataque de outras espécies de insetos, assim como observado em sementes de soja pelo teste de tetrazólio; a diferença é que, no teste de tetrazólio, o anel formado é de coloração avermelhada (França Neto et al., 1998). As sementes da classe 4 apresentaram endosperma de coloração clara, mas sem embrião visível. Sementes das classes 3 e 4 foram consideradas não germináveis.

Os valores obtidos pelo teste de germinação, e as diferentes classes de sementes, de acordo com o teste Lercafé, em todos os lotes estudados, encontram-se na Tabela 2. Ao se observarem os valores das diferentes classes, obtidos pelo teste Lercafé, nota-se que este foi eficiente para detectar a diferença na percentagem de germinação que havia entre os lotes, pois a soma dos valores das classes 1 e 2 - consideradas germináveis - e que corresponde à percentagem de germinação encontrada pelo teste Lercafé, diferiu entre os lotes e correspondeu aos valores encontrados pelo teste de germinação. Ao se analisar a percentagem de sementes encontradas nas classes 2 e 3 - sementes com danos por broca-do-cafeeiro - pode-se observar que o dano teve efeito significativo na germinação das sementes, pois o lote 4 , com maior percentagem de sementes das classes 2 e 3, teve sua germinação diminuída para $87 \%$. Os lotes 1 e 2 , que apresentavam menores quantidades de sementes das classes 2 e 3, não diferiram significativamente entre si. Além de se verificar a presença do dano por broca, é necessário quantificá-lo, pois este pode prejudicar a germinação das sementes, diretamente - lesão na região do embrião-e indiretamente-quando localizada distante do embrião -, pois a lesão favorece a incidência de fungos. Segundo Sousa \& Reis (1993), os principais danos causados pelo ataque da broca às sementes são: a perda de peso das sementes, em razão da destruição pelas larvas; o apodrecimento de sementes em frutos brocados que apresentam maturação forçada; e a inviabilidade de produção de sementes, pois os frutos brocados são descartados. Em relação às sementes da classe 4, não houve variação entre os lotes, e isto é atribuído ao fato de que o aparecimento de sementes sem embrião está relacionado ao campo de produção, à planta de origem ou ao processo de fertilização. Assim, como as sementes foram obtidas de uma única lavoura, esses valores semelhantes já eram esperados.

Outro resultado relevante é a presença de sementes brocadas, no tratamento testemunha (lote 1), visto que este, por análise visual, não as apresentava. Isso mostra ainda mais o potencial do teste Lercafé, pois ele foi capaz de detectar dano imperceptível a olho nu. Na Figura 3, é apresentada uma semente com dano

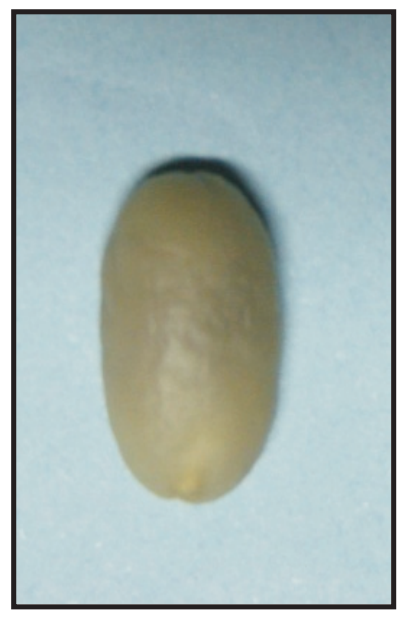

Classe 1

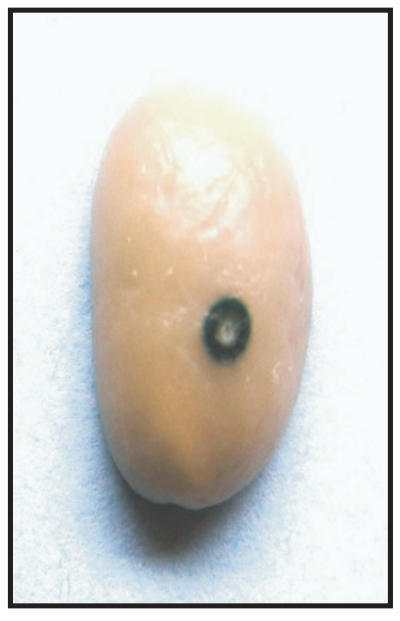

Classe 2

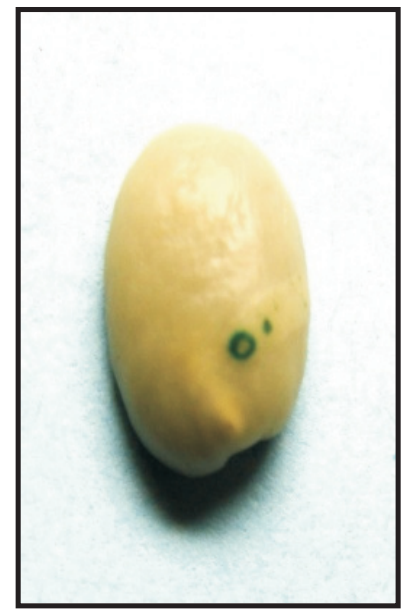

Classe 3

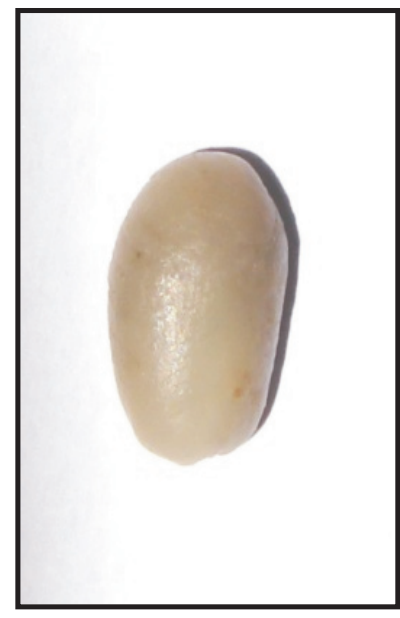

Classe 4

Figura 2. Classificação de sementes de cafeeiro pelo teste Lercafé. Classe 1, endosperma de coloração clara e embrião visível; classe 2, endosperma de coloração clara e lesão típica de ataque de broca, distante do embrião; classe 3, endosperma de coloração clara e lesão típica de ataque de broca, na região próxima ao embrião; classe 4, endosperma de coloração clara, sem embrião visível. 
causado pela broca-do-cafeeiro, que é imperceptível a olho nu, observado somente com uso de lupa (aumento de 6 vezes). A detecção desse tipo de dano

Tabela 2. Resultados dos testes Lercafé e de germinação, de lotes de café com diferentes percentagens de sementes danificadas por broca ${ }^{(1)}$.

\begin{tabular}{ccccccc}
\hline Lote $^{(2)}$ & $\begin{array}{c}\text { Teste de } \\
\text { germinação (\%) }\end{array}$ & $\begin{array}{c}\text { Germinação } \\
\text { Lercafé }(\%)^{(3)}\end{array}$ & \multicolumn{4}{c}{ Teste Lercafé (\%) } \\
\cline { 4 - 7 } & & $97 \mathrm{a}$ & 95 & 2 & 0 & 3 \\
\hline 1 & $91 \mathrm{ab}$ & $96 \mathrm{ab}$ & 90 & 6 & 2 & 2 \\
2 & $93 \mathrm{a}$ & $95 \mathrm{bc}$ & 87 & 8 & 3 & 2 \\
3 & $89 \mathrm{bc}$ & $94 \mathrm{c}$ & 80 & 14 & 3 & 3 \\
\hline & $87 \mathrm{c}$ & 0,64 & 2,33 & 22,55 & 66,75 & 22,73 \\
\hline CV $(\%)$ & 1,63 & & &
\end{tabular}

${ }^{(1)}$ Médias seguidas de letras iguais, nas colunas, não diferem entre si pelo teste de Tukey, a 5\% de probabilidade. ${ }^{(2)}$ Percentagem de sementes danificadas: lote $1,0 \%$; lote $2,5 \%$; lote $3,10 \%$; e lote $4,15 \%$. ${ }^{(3)}$ Corresponde às classes 1 e 2. ${ }^{(4)}$ Classes 1 e 2: germináveis; classes 3 e 4 : não germináveis.

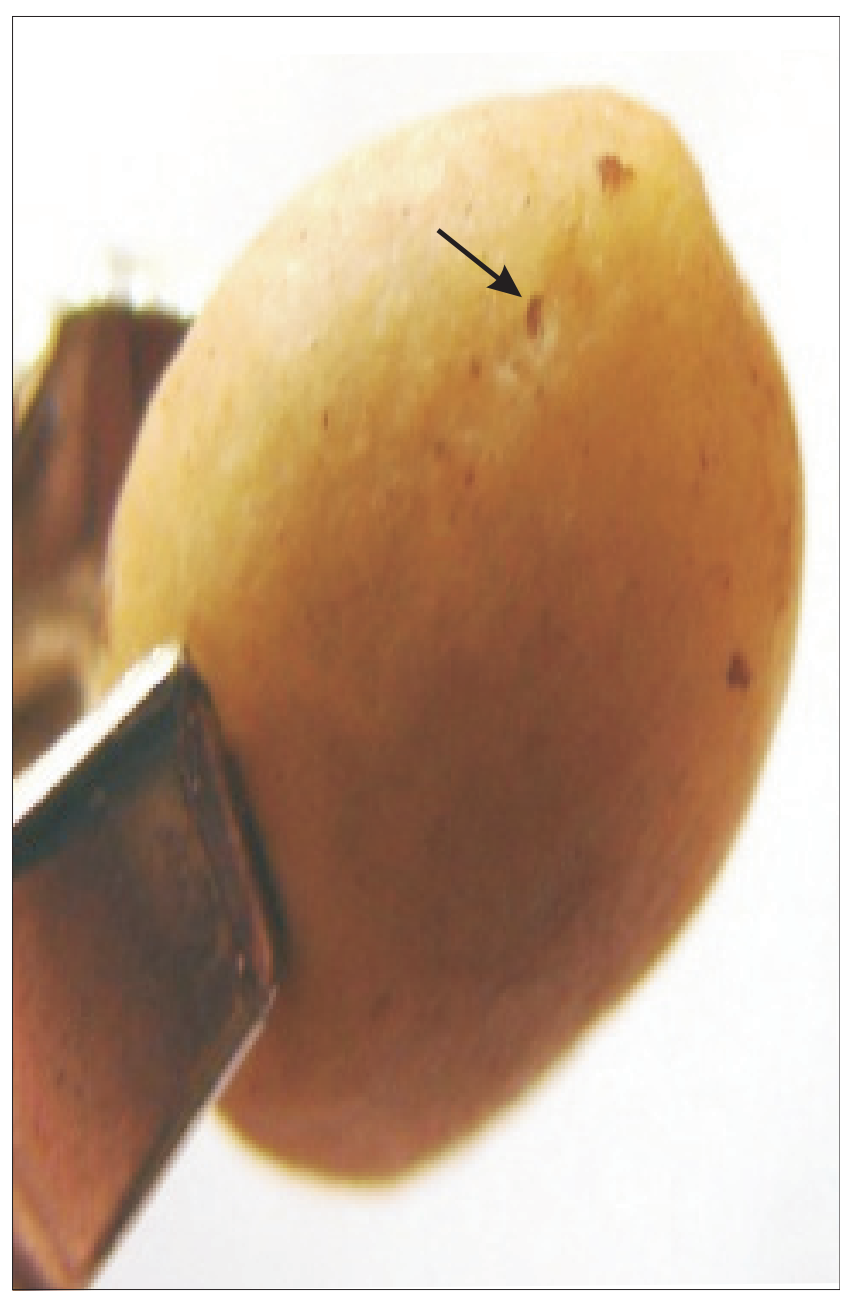

Figura 3. Semente de cafeeiro com dano causado por ataque de broca $(\longrightarrow$ ), visualizado com lupa (aumento de seis vezes). é de suma importância, principalmente quando se trata de café para bebida. Segundo Sousa \& Reis (1993), as conseqüências do ataque da broca, em relação à bebida, é a perda da qualidade pela depreciação do café, na classificação por tipo. A infestação da broca nos frutos altera indiretamente a qualidade de bebida do café, em razão da penetração de microrganismos nas galerias constituídas pelas fêmeas, o que causa o aparecimento de grãos do tipo vermelho.

Verificou-se correlação positiva e significativa $(r=0,80)$ entre os resultados obtidos pelos testes Lercafé e de germinação. O Lercafé pode ser utilizado para separar lotes de sementes com diferentes percentagens de germinação.

\section{Conclusões}

1. O teste Lercafé é eficiente para avaliar danos por secagem à alta temperatura e por broca, em sementes de cafeeiro.

2. O dano por secagem à alta temperatura caracterizase, por meio do teste Lercafé, pelo aparecimento de manchas esverdeadas espalhadas, que atingem parcial ou totalmente o endosperma da semente.

3. O dano por broca caracteriza-se, por meio do teste Lercafé, por uma depressão circundada por um anel de coloração verde.

\section{Agradecimentos}

Ao Conselho Nacional de Desenvolvimento Científico e Tecnológico, pelo financiamento.

\section{Referências}

ARAÚJO, E.F.; CORRÊA, P.C.; PEREIRA, O.A. Influência da temperatura de secagem na germinação de sementes de café. Revista Brasileira de Sementes, v.11, p.69-75, 1989.

BARBOZA, R.; HERRERA, J. El vigor en la semilla de café y su relación con la temperatura de secado, el contenido de humidad y las condiciones de almacenamiento. Agronomía Costarricense, v.14, p.1-8, 1990.

BATTISTI, A.; CANTINI, R.; FECI, E.; FRIGIMELICA, G.; GUIDO, M.; ROQUES, A. Detection and evaluation of seed damage of cypress, Cupressus sempervirens L. Seed Science and Technology, v.28, p.729-738, 2000.

BAUDET, L.M.; VILLELA, F.; CAVARIANI, C. Princípios de secagem. Seed News, v.3, p.20-22, 1999.

BORBÓN-MARTÍNEZ, O.; MORA-ALFARO, A.C.O.; OEHLSCHLAGER, A.C.; GONZÁLEZ, L.M. Proyecto de trampas, atrayentes y repelentes para el control de la broca del fruto 
de cafeto, Hypothenemus hampei Ferr. (Coleoptera: Scolytidae). In: SIMPOSIO LATINOAMERICANO DE CAFICULTURA, 19., 2000, San José. Memorias. San José: IICA-Promecafe, 2000. p.341-348.

BRASIL. Ministério da Agricultura e Reforma Agrária. Regras para análise de sementes. Brasília: SNDA, 1992. 365p.

DAMON, A. A review of the biology and control of the coffee berry borer, Hypothenemus hampei (Coleoptera: Scolytidae). Bulletin of Entomological Research, v.90, p.453-465, 2000.

FRANÇA NETO, J.B.; KRZYZANOWSKI, F.C.; COSTA, N.P. da. $O$ teste de tetrazólio em sementes de soja. Londrina: EmbrapaCNPSo, 1998. 72p. (Embrapa-CNPSo. Documentos, 116).

FLOR, E.P.O.; CICERO, S.M.; FRANÇA NETO, J. de B.; KRZYZANOWSKI, F.C. Avaliação de danos mecânicos em sementes de soja por meio da análise de imagens. Revista Brasileira de Sementes, v.26, p.68-76, 2004.

MACHADO, C.F. Metodologia para a condução do teste de germinação e utilização de raios-X para a avaliação da qualidade de sementes de aroeira-branca (Lithraea molleoides (Vell.) Engl.). 2002. 51p. Tese (Mestrado) - Escola Superior de Agricultura Luiz de Queiroz, Piracicaba.

MARCOS FILHO, J.; CÍCERO, S.M.; SILVA, W.R. Avaliação da qualidade das sementes. Piracicaba: Fealq, 1987. 230p.

OLIVEIRA, L.M. de. Avaliação da qualidade de sementes de canafístula (Peltophorum dubium (Sprengel) Taubet) pelos testes de germinação, tetrazólio e raios-X. 2000. 111p. Tese (Mestrado) - Universidade Federal de Lavras, Lavras.

PIMENTA, C.J.; VILELA, T.C. Efeito de diferentes porcentagens de grãos brocados no rendimento e atividade da polifenoloxidase em café (Coffea arabica L.) da região de Três Pontas, MG. Revista da Universidade de Alfenas, v.5, p.179-184, 1999.

PIMENTEL-GOMES, F. Curso de estatística experimental. 14.ed. Piracicaba: Nobel, 2000. 477p.

REIS, L.S. dos. LERCAFÉ: novo teste para estimar a germinação de sementes de cafeeiro (Coffea arabica L.). 2004. 57p. Dissertação (Mestrado) - Universidade Federal de Viçosa, Viçosa.

REIS, P.R.; SOUZA, J.C.; MELlES, C.A. Pragas dos frutos. Informe Agropecuário, v.10, p.41-50, 1984.

SOUSA, J.C.; REIS, P.R. Broca-do-café: histórico, reconhecimento, biologia, prejuízos, monitoramento e controle. Belo Horizonte: Epamig, 1993. 40p. (Boletim técnico, 50).

VIEIRA, A.R.; OLIVEIRA, J.A.; GUIMARÃES, R.M.; PEREIRA, C.E.; CARVALHO, F.E. de. Armazenamento de sementes de cafeeiro: ambientes e métodos de secagem. Revista Brasileira de Sementes, v.29, p.76-82, 2007.

VIEIRA, M.G.G.C.; GUIMARÃES, R.M.; PINHO, E.V.R.V.; GUIMARÃES, R.J.; OLIVEIRA, J.A. Testes rápidos para determinação da viabilidade e da incidência de danos mecânicos em sementes de cafeeiro. Lavras: Ufla, 1998. 34p. (Boletim Agropecuário, 26).

Recebido em 6 de agosto de 2008 e aprovado em 15 de outubro de 2008 
